\title{
Learning, Transitions, and Changing of the Guard
}

When I think of educational and developmental psychology, two words come to mind - learning, and transitions. Learning is of course the priority in formalised education, but also through our experiences across the lifespan. And as we grow and develop, transitions and change are inevitable. This edition of The Educational and Developmental Psychologist heralds another transition with a changing of the guard and an opportunity for personal reflection on learning and transitions as the incoming editor of the journal.

A number of years ago, I chose to embark on a career change and retrain as an educational and developmental psychologist. My first supervisor was instrumental in shaping my learning about conducting rigorous and meaningful research. This same supervisor introduced me to the world of scientific publishing and peer review, and created the opportunity to support this journal as a statistical consultant. To the outgoing editor, Chris Boyle, I owe a great debt of gratitude for the opportunities to learn so much under his tutelage. During his five-year tenure at the journal, Chris has successfully grown the international profile of the journal, increased the impact factor, and maintained the high standards of scientific rigour that are demanded in educational and developmental psychology. Indeed, much of the credit for the current edition is owed to Chris' work over the previous six months.

If it takes a village to raise a child, then it takes just as much support to prepare an academic for the role of journal editor. To the many mentors, lecturers, supervisors, colleagues, and especially clients who have taught me so much (and reminded me that I have so much more to learn), I am grateful. A special mention is reserved for my doctoral supervisor and colleague John Roodenburg for his mentorship, and he continues to support the journal in the role of associate editor. Such a significant transition for the journal is made that much easier with the support of colleagues like Chris, John, and many others.

The field of psychology is undergoing significant challenges both within Australia and internationally. Our colleagues in social psychology have found that sometimes research does not stand up to scrutiny and careful replication (Open Science Collaboration, 2015). Despite the best efforts of the scientific community, traditional peer review processes are flawed (Smith, 2006) and not necessarily indicative of quality research. These challenges and many others are just as pertinent to educational and developmental psychology, and it is incumbent on us to engage proactively with best practice in science. Transitioning from how we have done things in the past to how we will be doing things in the future is not always easy or comfortable. As educational and developmental psychologists, we are ideally placed to be able to manage transitions and learn new ways.

This edition includes a number of high quality research studies and comprehensive book reviews. Educational settings are increasingly being tasked with the role of 
supporting not only academic learning, but also wellbeing and mental health. Kiernan, Frydenberg, Deans, and Liang have investigated stress and coping in preschoolers from a measurement perspective, adding to the validity of the Children's Coping Scale Revised. Using an attachment lens, Goh and Wilkinson investigated interpersonal protective factors for adolescent stress and depression, with the findings helping to unpack some of the complexities of attachment, relationships, and mental health. Building on the research into adolescent depression and wellbeing, Zadow, Houghton, Hunter, Rosenberg, and Wood investigated causal pathways across time, concluding that focusing on wellbeing promotion alone may not be enough to address symptoms of depression. The book reviews cover a diverse range of topics, including a review by Morris of the Handbook of Australian School Psychology: Integrating International Research, Practice, and Policy, edited by Thielking and Terjesen; a review by Newell of Social and Emotional Learning in Australia and the Asia-Pacific: Perspectives, Programs, and Approaches, edited by Frydenberg, Martin, and Collie; and finally, a review by Stops of Making Sense of Interventions for Children With Developmental Disorders: A Guide for Parents and Professionals, edited by Bowen and Snow. None of these books are perfect (as scientist-practitioners we know better than to expect perfection), but all are great resources for educational and developmental psychologists.

Shane Costello

Editor

\section{References}

Open Science Collaboration. (2015). Estimating the reproducibility of psychological science. Science, 349(6251). doi:10.1126/science.aac4716

Smith, R. (2006). Peer review: A flawed process at the heart of science and journals. Journal of the Royal Society of Medicine, 99, 178-182. doi:10.1258/jrsm.99.4.178 